\title{
Nasal Deformity in Subjects with Class III Facial Deformities
}

\author{
Deformidad Nasal en Sujetos con Deformidad Facial Clase III
}

\author{
S. Olate*; M. Cantín"*; M. Muñoz ${ }^{* * * * * * * *}$;. P. Alister,"*****; B. Vásquez ${ }^{* * * * * * *}$ \& H. Chaves Netto******
}

OLATE, S.; CANTín, M.; MUÑOZ, M.; ALISTER, J. P.; VÁSQUEZ, B. \& CHAVES NETTO, H. Nasal Deformity in subjects with class III facial deformities. Int. J. Morphol., 33(4):1536-1541, 2015.

SUMMARY: Dentofacial deformities present some shades and variations that determine the inclusion of different anatomical components as part of the disease; the aim of this study was to ascertain the nasal characteristics in patients with a Class III dentofacial deformity. A descriptive study was conducted on 20 patients diagnosed with a Class III facial deformity and a surgical indication; frontal and lateral as well as CT images were taken to analyze variables of nasal morphology and deformities associated with the nasal bridge, tip and septum. The results showed that the nasal angles are outside normal parameters and that the basal width of the nose is approximately $3 \mathrm{~mm}$ smaller than the intercanthal width; $45 \%$ of the subjects have lateral deviations, $50 \%$ bridge deformity and $80 \%$ septum deviation. It is concluded that there are nasal deformities in subjects with a Class III facial deformity and that this component must be carefully evaluated in the preoperative stage.

KEY WORDS: Nasal deformity; Facial deformity; Facial morphology.

\section{INTRODUCTION}

Nasal characteristics have been analyzed in different studies where genetic considerations play an important role in their development and formation; other factors such as age and sex have also been important in ascertaining morphological differences (Broer et al., 2014).

In the cranial and nasoorbitoethmoid regions, growth develops significantly in the first 5 years of life. The growth and adaptation of nasal cartilages are progressive and related to the growth of the middle third of the face (D'Scanio et al., 2010). When there are facial deformities, the maxilla and mandible are frequently involved, so it is to be expected that in such a case the nose is also a component in the deformity.

Therefore, a facial deformity can cause the nose position to change, altering its sagittal or median relation, with deformities in the nasal bridge, deviations in the septum or nasal tip, among others.
Esthetic value is subjective and increases when dealing with the face. Ethnic and cultural conditions as well as level of education influence this value; thus, the observer can define alterations of facial esthetics or normality. There are anthropometric parameters that define the relation of the nose in the facial context such that in the presence of facial normality, the nose must use wellknown values; however, ethnic and racial differences pose great differences, which are at times not sufficiently valued (Farkas et al., 2005).

In subjects with a facial deformity changes can be seen in proportional normality and facial harmony; known patterns are altered or lost in these subjects, generally determining the diagnosis and surgical treatment (Sato et al., 2014). Although functional and esthetic nasal surgery is frequently used, the nasal parameters associated with subjects with maxillomandibular facial deformities are not clear.

\footnotetext{
Division of Oral and Maxillofacial Surgery, Universidad de La Frontera, Temuco, Chile.

** Dental School, Universidad de La Frontera, Temuco, Chile.

*** Centro en Investigaciones Biomédicas, Universidad Autónoma de Chile, Temuco, Chile.

**** Fellow Research, Universidad Científica del Sur, Lima, Perú.

****** PhD Program in Medical Sciences, Universidad de La Frontera, Temuco, Chile.

******* Universidad de Tarapacá, Arica, Chile.

******** Division of Oral and Maxillofacial Surgery, Dental School, Universidade Federal de Juiz de Fora, MG, Brazil. Funded by Project DI14-0049, Universidad de La Frontera, Temuco, Chile.
} 
On the other hand, the surgical treatment of subjects with facial deformities has modified substantially in the last 20 years, determining that esthetic refinements of the face are complementary to orthognathic surgical procedures (O’Ryan \& Lassetter, 2011), including management at different levels of the face.

The aim of this study was to define the presence of nasal deformity in subjects with a Class III skeletal deformity and relate it to analysis variables.

\section{MATERIAL AND METHOD}

A descriptive study was designed to analyze the nasal morphology in subjects with a Class III sagittal facial deformity with or without facial asymmetry. Subjects aged between 15 and 30 years were included, both sexes, who voluntarily presented for diagnosis and the possibility of surgical treatment for facial deformities of the middle and lower third of the face. Subjects with facial malformations, previous facial trauma, surgeries on the face and subjects with non-Class III facial deformities were excluded. Classification of the type III deformity was based on the presence of an overjet of at least $-1 \mathrm{~mm}$ and the presence of a Sella-Nasion-A Point (SNA) angle less than $80^{\circ}$.

The diagnosis protocol for the deformity included clinical facial analysis, 2D imaging analysis and study with cone beam computed tomography (CBCT).

2D imaging. 2D images were taken according to the protocol of Schaaf et al. (2006) and Ettorre et al. (2006), identifying focal points on the frontal and right lateral areas of the face. Both images were taken 3 times, with the head in a natural position, horizontal view and with the bipupilar plane parallel to the floor.

In the frontal image the focal point was the nasion point. The distance between the camera and subject was 2 $\mathrm{m}$, with standardized lighting conditions using the amount of light, ISO sensitivity 100 and $105 \mathrm{~mm}$ macro lens. A Canon EOS Rebel t5 (Canon Inc., Tokyo, Japan) camera was used. The lateral images followed the same parameter and were obtained with a focal point at the level of the zygomatic arch with the intersection of the line descending from the exocanthion, following the protocol proposed by Schaaf $e t$ $a l$. and Ettorre $e t$ al.

The image was then analyzed using Adobe Photoshop, Elements 11.0 Editor (Adobe System Inc., USA), incorporating the image to study the position of the chin in relation to the facial midline, an angulation obtained with the outer edges of the lips.

3D imaging. The CT images were taken on the PlanMeca ${ }^{\circledR}$ unit (Pax Zenith, Vatech, Korea, 2011), using $90 \mathrm{kV}$ and $120 \mathrm{~mA}$, at the Dental Clinic Imaging Center of the Universidad de La Frontera, and were analyzed with the software EZ3D plus (2009), by a single operator on three occasions at two-week intervals from the first measurement. The subjects were placed in a natural head position with positioners located on the right and left supraorbital lateral areas.

Image Analysis. 1. Frontal image (Fig. 1): The position of the nose was analyzed in relation to the facial midline, establishing deviation of the nasal tip towards the right or left. Additionally, the distance between the right and left endocanthion points was measured; similarly, the horizontal parallel to the bipupilar plane was measured from the most lateral points of the alar region of the right and left nostrils.

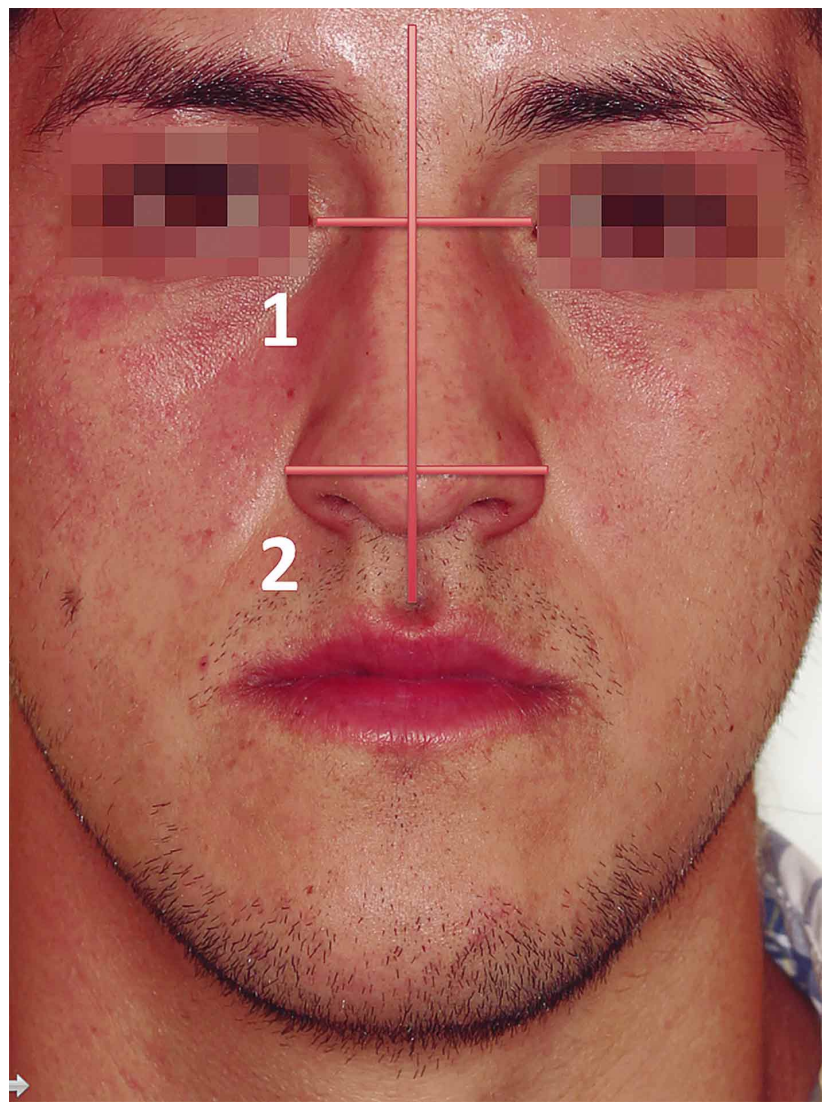

Fig. 1. Frontal image. The intercanthal distance (1) and interalar distance (2) was studied. The midline of the face was estimated by the point between the glabella and chin, where the pronasale was determined and its relation to the midline. 
2. Lateral image (Fig. 2): The nasal deformity was identified by the presence of a "hump" in the nasal bone area. With this same image superior nasal angles were obtained, from the nasal tip and from the nasal base with labial superior. 3. Computed tomography (Fig. 3): An analysis was made of the coronal and axial cuts of the nasal septum. The presence of deviation of the nasal midline was observed as well as the direction towards which the deviation was generated.

All the measurements were taken at three different points by the same observer; the final measurement was obtained from the average of the three measurements. The intraclass correlation coefficient was used to evaluate the statistical error.

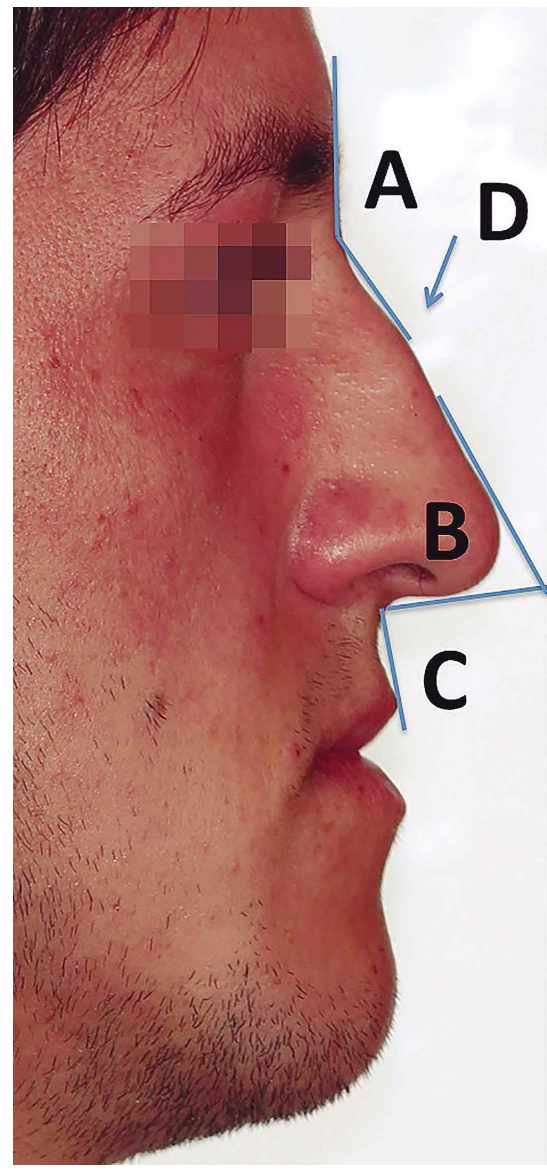

Fig. 2. Lateral image. Angles were studied, where 1 corresponds to the superior angle (glabella-nasion-pronasale), 2 to the angle that generates the nasal tip and 3 to the nasolabial angle. The area indicated with the arrow determines the point at which the nasal bridge deformity is assessed.

\section{RESULTS}

Twenty subjects with a Class III facial deformity were analyzed. All of them had a SNA angle less than $80^{\circ}$ and an overjet of $-1 \mathrm{~mm}$ or more. $60 \%$ (12 subjects) were female and 8 subjects $(40 \%)$ were male. The average age of the subjects was 21.4 years. The analysis of intraclass measures showed a correlation between the measures of 0.98 with a $p$ value of 0.001 .

An average intercanthal width of $38 \pm 8.95 \mathrm{~mm}$ was observed. The interalar width was $35 \pm 11.32 \mathrm{~mm}$, which determined an average intercanthal width $3 \mathrm{~mm}$ greater than the interalar width.

With respect to the analysis of nasal deformities, the presence of a lateral deviation with deviation of the tip was observed in $45 \%$ and deformities of the nasal hump in 50\%. The coronal and axial CT image showed deviation of the nasal septum in its mid and lower part in $80 \%$ of the cases (4 subjects did not have septum deviation).

The nasal angles observed in the lateral image were shown to be $144 \pm 21.21^{\circ}$ in the superior angle, $90 \pm 21.21^{\circ}$ in the nasal tip and $81 \pm 26.24^{\circ}$ in the nasal base with the labial superior.

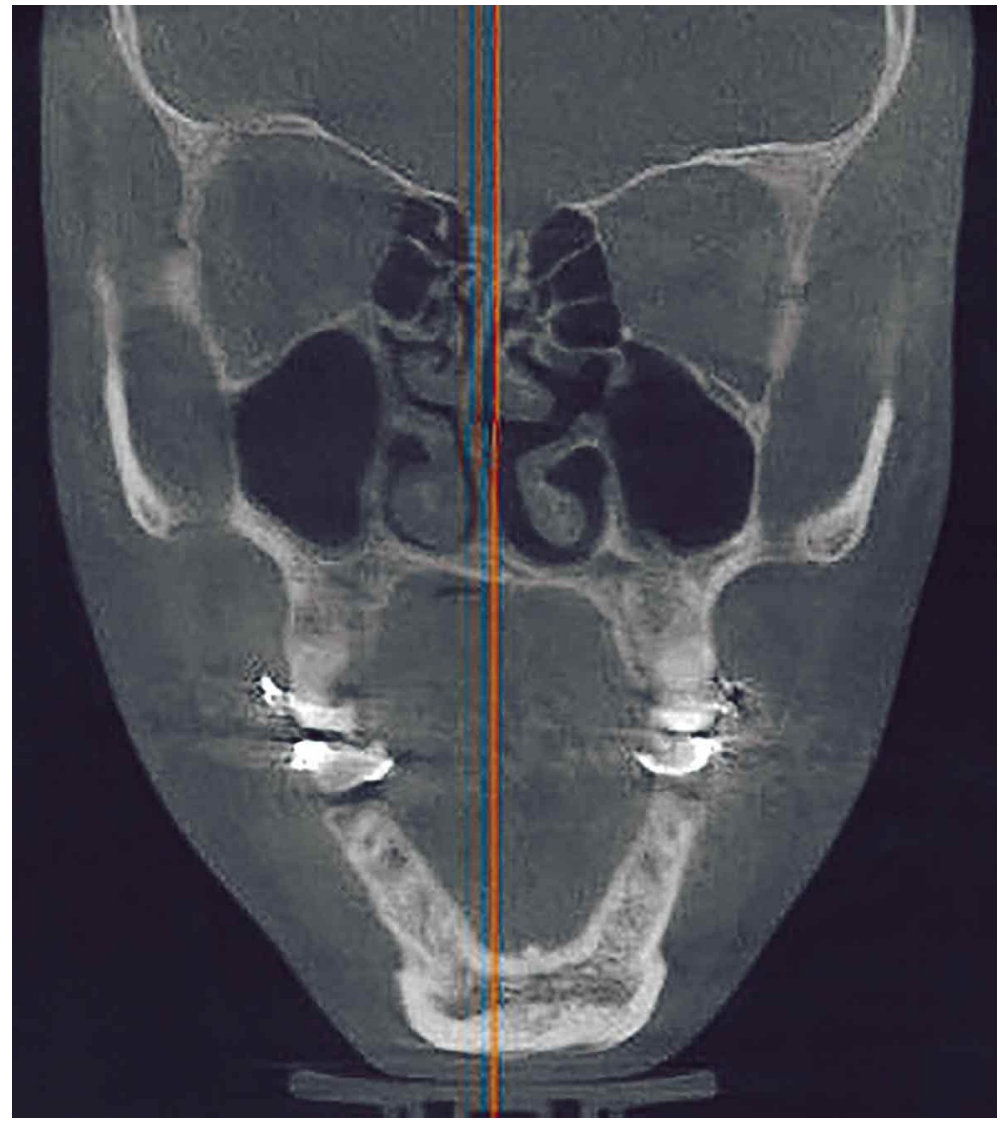

Fig. 3. Coronal cut of CT image. Septum deviation was identified by identifying the midline and its relation to the septum. 


\section{DISCUSSION}

Facial morphology has been analyzed by different authors with a wide variety of options. Objectivity in this type of analysis has been complicated due to the multiple variables associated with the condition, including ethnicity, culture and the age of the individual as important elements in the assessment (Farkas et al.).

In an attempt to provide objective answers to the questions surrounding normal facial morphology, the studies by Leslie G. Farkas stand out for developing this line of enquiry (Farkas et al.). In this context, starting from the lines of Farkas et al. and Koury \& Epker (1992) established a series of parameters to determine facial normality in subjects with facial deformities. To date, this proposal is considered within the treatment canons and objectives.

The established norm for the superior nasal angle (glabella-nasion-pronasale) is $132 \pm 15^{\circ}$, whereas in our sample this angle was greater by almost $12^{\circ}$. The nasolabial angle (lower angle that relates the nasal base to the labial superior) presents a norm from $90^{\circ}$ to $110^{\circ}$, but in our sample it showed a value less than $81^{\circ}$. Previous studies by Olate $e t$ al. (2014a, 2014b) showed this same nasolabial angle in Class III subjects with values of $100^{\circ}$, which stayed within the norm and creates confusion when comparing it to the present results.

Variations in the bone morphology of the nose can influence the results (2014a, 2014b). Likewise, the reduced nasolabial angle observed in this study may be associated with subjects with a Class III deformity, and poor maxillary growth presents an anterior nasal spine with retruded position, which makes descent of the nasal tip possible and with it a reduction in the nasolabial angle. The norms and proportions of normality reported by Koury \& Epker place this condition outside normality.

However, Koury \& Epker determined that the width of the alar base must be equal to the distance between the right and left endocanthions. In our sample there is a difference of $3 \mathrm{~mm}$, with the interalar width being smaller than the intercanthal width. Like the situation observed with the nasolabial angle, the reduced width of the alar base may be caused by deficient maxillary growth and the reduction in the size of the pyriform aperture.

Orthognathic surgery at maxillary level impacts on the nasal architecture and anatomy. These procedures objectively mobilize the nose three-dimensionally; Dantas et al. (2015) reported that surgery for anterior and superior maxillary repositioning produces movements of the nasal tip upward in $85 \%$ of the cases, advancement of the tip in $80 \%$, rotation of the tip in $80 \%$ and widening of the nasal base in $95 \%$, causing significant cosmetic changes in this area.

The cosmetic aspects involved in treatment with orthognathic surgery determine the need for complementary procedures to acquire facial harmonization. Ribiony et al. (1998) presented a series of 17 patients who received polyethylene implants in the sector of the zygomatic bone to achieve a greater paranasal projection together with maxillary advancement surgery. Recently, Mohamed \& Perenack (2014) conducted a review, describing the sequence and management of combined esthetic and orthognathic surgery, where the authors emphasized that the impact of orthognathic procedures on nasal value may be due to the anatomical condition of the nose or the nasal projection that can be achieved once the bone movements have been made, where the final chin position can influence the perception of the nasal esthetic.

One of the first studies to use simultaneous nose and maxillary surgery was conducted by Waite et al. (1988), who operated on 22 patients, determining the protocol for managing intubation of the patient and the surgical sequence, making this technique a real possibility for achieving cosmetic and functional objectives.

Thus, the simultaneous surgical treatment of nose and maxilla has been identified with clarity. Costa et al. (2008) studied 13 patients who underwent maxillary surgery with a Le Fort I osteotomy, rhinoseptoplasty with or without osteotomies and subsequent nasal endoscopic surgery for managing the middle turbinate and/or meatus region, reporting success in the combined therapy.

Esthetic nasal surgery improves the patient's quality of life and satisfaction. Baykal et al. (2014) published a series of 47 patients who presented "hump deformities" and "nasal axis deviations", which were treated with open or closed rhinoplasty; satisfaction from $21 \%$ to $72 \%$ was observed in the postoperative stage, with significant differences in all the assessments. Studies by Uzun \& Ozdemir (2014) also showed similar results.

Our investigation revealed that $45 \%$ of the subjects with a Class III dentofacial deformity presented lateral deviations and 50\% deformities in the nasal bridge. The latter condition may be associated with anatomical conditions where the anterior nasal spine appears posterior, causing the nasal tip to descend and altering the normal morphology of the nose. On the other hand, our results showed that the 
deviated septum appeared in $80 \%$ of the cases, which could also be associated with deficient maxillary growth and the resulting nasal floor. With these conditions, corrective maxillary surgery must include an analysis of nasal surgery, since the deformity observed in this structure requires at least a preoperative assessment. Septum deviation can also cause respiratory disorders such as nasal obstruction.

An interesting study by D'Ascanio et al. indicated that subjects from 7 to 12 years with septum deviation displayed anomalies in dental and facial development, and one hypothesis is that the presence of septum deviation is prior or parallel to the development of the facial deformity and this condition also contributes to limiting adequate maxillary growth.

Performing orthognathic surgery on 75 patients, Seah et al. (2012) revealed that $61 \%$ had nasal deformities with no significant differences between Class II and Class III subjects; the authors noted that only $19 \%$ presented chin deformities that required some type of surgery; the most common nasal deformities were those of the tip and the bridge. Our results tend toward those of Seah et al.

Based on our results, almost $50 \%$ of the patients with Class III dentofacial deformities present nasal deformities; septum deviation appears in $80 \%$, establishing the need for study in this area.

\section{ACKNOWLEDGEMENT}

The authors are grateful for the support to the Project DI14-0049, Universidad de La Frontera, Temuco, Chile.

OLATE, S.; CANTÍN, M.; MUÑOZ, M.; ALISTER, J. P.; VÁSQUEZ, B. \& CHAVES NETTO, H. Deformidad nasal en sujetos con deformidad facial clase III. Int. J. Morphol., 33(4):1536-1541, 2015.

RESUMEN: Las deformidades dentofaciales presentan algunos matices y variaciones que determinan la inclusión de diferentes componentes anatómicos dentro de la enfermedad; el objetivo de esta investigación es conocer las características de la nariz en pacientes con deformidad dentofacial de clase III. Se desarrollo un estudio descriptivo en 20 pacientes con diagnóstico de deformidad facial declase III e indicación quirúrgica; se estudiaron análisis fotográficos frontales y laterales así como tomografías computadorizadas para analizar variables de morfología nasal y deformidades asociadas al puente nasal, punta nasal y septo nasal. Los resultados demostraron que los ángulos nasales se encuentran fuera de los parámetros de normalidad y que el ancho basal de la nariz es aproximadamente 3 mm menor que el ancho intercantal; el 45\% de los sujetos presentó desviación lateral, 50\% deformidad del puente nasal y el 80\% desvío de septo nasal. Se concluye que existen deformidades nasales en sujetos con deformidad facial de clase III y que este componente debe ser evaluado criteriosamente en la etapa preoperatoria.

PALABRAS CLAVE: Deformidad nasal; Deformidad facial; Morfología facial.

\section{REFERENCES}

Baykal, B.; Erdim, I.; Kayban, F. T. \& Oghan, F. Comparative analysis of nasal deformities according to patient satisfaction. J. Oral Maxillofac. Surg., 72(3):603.e1-7, 2014.

Broer, P. N.; Juran, S.; Liu, Y. J.; Weichman, K.; Tanna, N.; Walker, M. E.; Ng, R. \& Persing, J. A. The impact of geographic, ethnic, and demographic dynamics on the perception of beauty. $J$. Craniofac. Surg., 25(2):e157-61, 2014.

Costa, F.; Robiony, M.; Salvo, I.; Toro, C.; Sembronio, S. \& Politi, M. Simultaneous functional endoscopic sinus surgery and esthetic rhinoplasty in orthognathic patients. J. Oral Maxillofac. Surg., 66(7):1370-7, 2008.

Dantas, W. R.; da Silveira, M. M.; do Egito Vasconcelos, B. C. \& Porto, G. G. Evaluation of the nasal shape after orthognathic surgery. Braz. J. Otorhinolaryngol., 81(1):19-23, 2015.
D’Ascanio, L.; Lancione, C.; Pompa, G.; Rebuffini, E.; Mansi, N. \& Manzini, M. Craniofacial growth in children with nasal septum deviation: a cephalometric comparative study. Int. J. Pediatr. Otorhinolaryngol., 74(10):1180-3, 2010.

Ettorre, G.; Weber, M.; Schaaf, H.; Lowry, J. C.; Mommaerts, M. Y. \& Howaldt, H. P. Standards for digital photography in craniomaxillo-facial surgery - Part I: Basic views and guidelines. $J$. Craniomaxillofac. Surg., 34(2):65-73, 2006.

Farkas, L. G.; Katic, M. J.; Forrest, C. R.; Alt, K. W.; Bagic, I.; Baltadjiev, G.; Cunha, E.; Cvicelová, M.; Davies, S.; Erasmus, I.; Gillett-Netting, R.; Hajnis, K.; Kemkes-Grottenthaler, A.; Khomyakova, I.; Kumi, A.; Kgamphe, J. S.; Kayo-daigo, N.; Le, T.; Malinowski, A.; Negasheva, M.; Manolis, S.; Ogetürk, M.; Parvizrad, R.; Rösing, F.; Sahu, P.; Sforza, C.; Sivkov, S.; Sultanova, N.; Tomazo-Ravnik, T.; Tóth, G.; Uzun, A. \& Yahia, 
OLATE, S.; CANTÍN, M.; MUÑOZ, M.; ALISTER, J. P.; VÁSQUEZ, B. \& CHAVES NETTO, H. Nasal Deformity in subjects with class III facial deformities. Int. J. Morphol., 33(4):1536-1541, 2015.

E. International anthropometric study of facial morphology in various ethnic groups/races. J. Craniofac. Surg., 16(4):61546, 2005.

Koury, M. E. \& Epker, B. N. Maxillofacial esthetics: anthropometrics of the maxillofacial region. J. Oral Maxillofac. Surg., 50(8):806-20, 1992.

Mohamed, W. V. \& Perenack, J. D. Aesthetic adjuncts with orthognathic surgery. Oral Maxillofac. Surg. Clin. North Am., 26(4):573-85, 2014.

Olate, S.; Cantín, M.; Vásquez, B. \& Olate, G. Structure of the nose in patients with class III facial deformities. Int. J. Morphol., 32(1):334-8, 2014a.

Olate, S.; Cantín, M.; Vásquez, B.; del Sol, M. \& de Moraes, M. Facial Soft Tissue in Subjects with Class II and Class III Facial Deformities: Preliminary Results. Int. J. Morphol., 32(3):1022-5, 2014b.

O’Ryan, F. \& Lassetter, J. Optimizing facial esthetics in the orthognathic surgery patient. J. Oral Maxillofac. Surg., 69(3):702-15, 2011.

Robiony, M.; Costa, F.; Demitri, V. \& Politi, M. Simultaneous malaroplasty with porous polyethylene implants and orthognathic surgery for correction of malar deficiency. J. Oral. Maxillofac. Surg., 56(6):734-41, 1998.

Sato, F. R.; Mannarino, F. S.; Asprino, L. \& de Moraes, M. Prevalence and treatment of dentofacial deformities on a multiethnic population: a retrospective study. Oral Maxillofac. Surg., 18(2):173-9, 2014.

Schaaf, H.; Streckbein, P.; Ettorre, G.; Lowry, J. C.; Mommaerts, M. Y. \& Howaldt, H. P. Standards for digital photography in cranio-maxillo-facial surgery--part II: additional picture sets and avoiding common mistakes. J. Craniomaxillofac. Surg., 34(6):366-77, 2006.

Seah, T. E.; Bellis, H. \& Ilankovan, V. Orthognathic patients with nasal deformities: case for simultaneous orthognathic surgery and rhinoplasty. Br. J. Oral Maxillofac. Surg., 50(1):55-9, 2012.

Uzun, A. \& Ozdemir, F. Morphometric analysis of nasal shapes and angles in young adults. Braz. J. Otorhinolarybgol., 80(5):397-402, 2014.

Waite, P. D.; Matukas, V. J. \& Sarver, D. M. Simultaneous rhinoplasty procedures in orthognathic surgery. Int. J. Oral Maxillofac. Surg., 17(5):298-302, 1988.

\author{
Correspondence to: \\ Prof. Sergio Olate \\ Division of Oral and Maxillofacial Surgery \\ Universidad de la Frontera \\ Claro Solar 115, Oficina 404B \\ Temuco \\ CHILE
}

Email: sergio.olate@ufrontera.cl

Received: 07-07-2015

Accepted: 15-09-2015 